\title{
Lifetime Experiences Scale (LIFES): Development and validation in community samples
}

\author{
Vanessa Azevedo ${ }^{1}$, Carla Martins² \& Ângela Maia ${ }^{2}$ \\ ${ }^{1}$ Universidade Fernando Pessoa, Porto, Portugal \\ ${ }^{2}$ Escola de Psicologia, Universidade do Minho, Braga, Portugal
}

\begin{abstract}
This paper describes the development, validation, and reliability of a new measure to assess life experiences reported by adults, the Lifetime Experiences Scale (LIFES). This scale is important because no available measure focuses on both positive and negative life experiences and covers childhood, adolescence, and adulthood. LIFES is a self-report measure consisting of two sections: 75 items (organized into eight domains: school, work, health, leisure, life conditions, adverse experiences, achievements, and people and relationships) regarding lived experiences and blank spaces for non-lived (but desired) experiences. The procedures involved in the development of LIFES are described in detail (e.g., construct, generation of items and questions). Moreover, evidence based on test content, response processes, relations to other variables, and different classes of reliability for community samples are presented. Overall, the results suggest that LIFES presented good evidence of validity and reliability and can be a valuable tool for research and clinical purposes.
\end{abstract}

Keywords: Developmental psychology; life events; reliability; lifespan; retrospective; self-report.

Lifetime Experiences Scale (LIFES): Desenvolvimento e validação em amostras da comunidade. Este artigo descreve o processo de desenvolvimento e validação de um novo instrumento para avaliar experiências de vida, reportadas por adultos: a Lifetime Experiences Scale (LIFES). A originalidade deste instrumento prende-se com a inclusão quer de experiências positivas, quer negativas ocorridas na infância, adolescência e vida adulta. A LIFES é uma medida de autorrelato organizada em duas secções: 75 itens (abrangendo oito domínios: percurso escolar, percurso profissional, saúde, tempos livres, condições de vida, experiências adversas, realizações e pessoas e relações) sobre experiências vividas e espaços em branco para as experiências não vividas (mas desejadas). Os procedimentos realizados para o desenvolvimento da LIFES são apresentados detalhadamente (e.g., construto, criação de itens e questões). Além disso, são apresentadas evidências baseadas no conteúdo, processo de resposta, relação com outras variáveis e diferentes tipos de fiabilidade, em amostras da comunidade. Genericamente, os resultados da LIFES indicam boas evidências de validade e fiabilidade, apresentando-se como um instrumento útil quer para fins de investigação, quer clínicos.

Palavras-chave: Psicologia do Desenvolvimento; eventos de vida; consistência; ciclo de vida; avaliação retrospetiva; autorrelato.

Although life experiences are not a new topic of research or clinical interest (Paykel, 2001), they remain a relevant issue crossing different fields of psychology. After reviewing and analyzing the currently available measures, such as the Life Events Checklist (Gray, Litz, Hsu, \& Lombardo, 2004), we drew several important conclusions about the conceptual and technical challenges in this field of assessment.

First, there is a clear imbalance between the assessment of positive and negative life experiences, which consequently affects the availability of empirical results. Research on negative life experiences, which are also labeled traumatic or stressful events (depending on the theoretical perspective), has a long tradition and a rich variety of published studies and available self-report measures; the opposite is true for positive life experiences (with a few exceptions, such as the Life Experiences Survey by Sarason, Johnson, \& Siegel, 1978). This trend affects psychology in general (Bausmeister, Bratslavsky, Finkenauer, \& Vohs, 2001) and this research line in particular (Zimmerman, 1983). Second, we realized that no

\footnotetext{
1 Correspondence address: Vanessa Azevedo, Universidade Fernando Pessoa, Praça 9 d abril, n.o 349, 4249-004 Porto. E-mail: vanessa.mazev@gmail.com. This work was part of a doctoral thesis, supported by the Foundation for Science and Technology, through the individual grant SFRH/BD/76022/2011, with funds from POQH - QREN - Tipologia 4.1 - Formação avançada, financed by European Social Funds and the Portuguese State Budget. This study was conducted at the Psychology Research Centre (PSI/01662), School of Psychology, University of Minho, supported by the Foundation for Science and Technology (FCT) through the Portuguese State Budget (Ref.: UIDB/PSI/01662/2020).
} 
scientific definition of life experiences exists; rather, this term appears to refer to a shared concept that does not require an objective, clear definition. Additionally, we noticed that the labels life experiences and life events are used interchangeably. Another problem was the scarcity of a lifespan perspective (Dohrenwend, 2006), evidenced by the absence of measures covering lifetime experiences using a temporally organized schema. For instance, some instruments were organized around developmental stages (i.e., childhood and/or adolescence), whereas others focused on events throughout the lifespan (but did not collect data concerning when these events occurred). We further concluded that most measures did not allow individuals to reflect on their own life experiences; instead, these instruments established a valence (positive or negative) based on general consensus while ignoring personal experiences (e.g., the birth of a child is a positive event for most people but not necessarily for all). This was the starting point for the development and evaluation of the Lifetime Experiences Scale (LIFES).

\section{LIFES: WHAT IS NEW?}

LIFES was designed to overcome previous limitations and to assess personal life experiences, both positive and negative, that occur throughout the lifespan while independently considering childhood, adolescence, and adulthood. Moreover, LIFES, whose target population is adults, is a self-report measure that presents singular advantages: It is rooted in a clearly defined construct of life experiences (presented below), covers a comprehensive and varied set of life experiences (which can be assessed as a whole or by specific domains, according to specific aims); it allows the realization of (dis)continuity in patterns of life experiences (e.g., if sexual abuse occurred only in childhood or also throughout adulthood); and it includes a section devoted to non-lived (but desired) experiences. Furthermore, LIFES differs from other available measures due to its nonjudgmental style (allowing participants to freely evaluate their own experiences) and greater flexibility (e.g., two unusual answers are available, i.e., not remember regarding occurrence and neutral regarding valence).

This measure allows the easy and detailed collection of life experiences in a less threatening manner ${ }^{2}$; therefore, it is promising for research and clinical purposes in different fields of psychology (e.g., clinical, health, justice). This paper describes the development and evidence of the validation and reliability of LIFES in community samples.

\section{DEVELOPMENT}

\section{Definition of construct}

As previously mentioned, LIFES was developed to assess lifetime experiences, both positive and negative, from all developmental stages, with adults as the target population. The construct being studied was life experiences, which, in the absence of a formal scientific definition, was defined as a set of events (I was born...), conditions (I live/lived...), and perceptions (I feel/felt...) that occur (or not) during a lifetime. According to this definition, life experiences include, but are not limited to, life events ${ }^{3}$. Additionally, life experiences are not limited to self; instead they also embrace the individual's environment, other relevant people and the interactions among them. The focus of life experiences is personal and it includes two types of features: an objective (regarding the occurrence and the developmental stage) and a subjective (regarding the valence and the impact). Consequently, although the occurrence of life events, conditions, and perceptions can be shared, it is unlikely that two people experience them in exactly the same way and even the same individual can change the subjective features throughout the lifespan.

\section{Generation and selection of items}

After the operational definition of life experiences was established, we assembled a pool of items ( $N=967)$ based on an extensive literature review; an analysis of preexisting measures of life event; brainstorming exercises with psychology graduate students; interviews with children, adolescents, and adults concerning positive and negative life experiences; and researchers' proposals. This pool of items constituted a comprehensive set of life experiences that occur, with heterogeneous frequency, in a community population throughout the lifespan. This initial set of items was organized by category (relationships; health/illness; care/abuse experiences; school/job; legal problems; life conditions; leisure; spirituality; accidents; perceptions about the self; awards and acknowledgments; learning; gifts and acquisitions; and historical events). Repeated items were then removed, and the remaining items were organized according to the likely period of occurrence (e.g., pregnancy can occur during adolescence or adulthood).

\footnotetext{
${ }^{2}$ Comparing our past experience using other measures with LIFES, we noticed that participants tended to be less reluctant to answer a measure that included both positive and negative experiences (vs. only negative).

${ }^{3}$ Life events seem to represent a narrower set of single, concrete and highly temporally defined (e.g., marked beginning and ending) events.
} 
Items were selected based on their frequency in the initial pool: We identified the most frequently reported life experiences (positive and negative) in each category. Additionally, we included life experiences that were reported less often but were nonetheless quite relevant (e.g., sexual abuse). Lastly, some unusual items were excluded (e.g., drinking hot chocolate, which was a positive life experience for one participant).

The wording of items was a concern at this step; once again, the available measures were reviewed. Because the initial, "first generation" (Zimmerman, 1983) of measures included broad, unspecific items and the attendant problem of intracategory variability (Dohrenwend, 2006), a "second generation" of measures emerged that included more descriptive and specific items (Zimmerman, 1983). To avoid the limitations of the "first-generation" measures and to improve accuracy, the LIFES items were worded in a descriptive, specific, nonjudgmental, and (whenever possible ${ }^{4}$ ) behavioral manner (e.g., "receiving affection" was replaced by "to be hugged, kissed").

\section{Selection of questions and answers}

The selection of questions and the measure scales were based on the purposes of the current study and on a literature review (Casey, Masuda, \& Holmes, 1967; Dohrenwend, 2006; Paykel, 1983; Zimmerman, 1983). After discussing other characteristics of life experiences (e.g., desirability and predictability) and considering the need to prevent LIFES from becoming overwhelming, we selected four questions associated with an appropriate answer scale. LIFES included questions about the following types of issues: (a) Occurrence: Did you live? with three options (yes; no; do not remember ${ }^{5}$ ); (b) Developmental stage: When? with three, not mutually exclusive, options (childhood; adolescence; adulthood); (c) Valence: For me it was a ... experience, with three options (positive; negative; neutral); (d) Impact: How much did it affect/influence your life? with a 5-point Likert scale ranging from 0 (not at all) to 4 (absolutely).

\section{Organization of items}

After the items and questions were selected, a preliminary version of LIFES was developed. This version included three independent sections - childhood, adolescence, and adulthood - in an effort to facilitate the cognitive tasks involved, such as memory and attention (Fowler, 1995). However, the temporal frame implied that some items were presented in more than one section (sometimes in all of the sections). To test this version of LIFES, a pilot study was conducted to analyze the participants' tolerance for its length. According to the feedback received, the repetition present in the measure caused it to be too long. To overcome this problem, a new version of LIFES was proposed in which the temporal framework was replaced by a thematic organization. According to the work of Conway et al. (e.g., Burt, Kemp, \& Conway, 2003; Conway, 2005; Conway \& Pleydell-Pearce, 2000), autobiographical memory is organized by themes; therefore, we hypothesized that the task would be easier for participants if the items were grouped. In the second version, the items were grouped into themes (e.g., school), which significantly reduced the length of LIFES without increasing the difficulty level.

The assessment of lived experiences and non-lived experiences was another organizational feature that was discussed. At an initial proposal, we requested that the participants answer the same items in terms of both lived and non-lived experiences; however, this task was perceived as quite confusing and difficult. Because the concept of life experiences includes non-occurrences (e.g., the birth of a child) and because some authors claim that non-lived experiences can be relevant (e.g., Gersten, Langner, Eisenberg, \& Orzek, 1974), we included lived experiences and non-lived experiences as two distinct sections.

\section{DESCRIPTION OF LIFES}

LIFES is composed of two sections: lived experiences and non-lived (but desired) experiences; due to the inclusion of several sex-specific items (e.g., pregnancy), LIFES is available in female and male versions, namely 19 items have different formulations for female and male. Its paper-and-pencil completion requires 30 minutes on average.

The lived experiences section includes 75 items $(70$ concerning life experiences plus five filter items), which are organized into the following eight domains: school (one filter item plus seven items), work (one filter item plus three items), health (eight items), leisure (six items), life conditions (seven items), adverse experiences (five items), achievements (four items), and people and relationships (three filter items plus 29 items). Because not all items apply to everyone, the filter items were included to determine whether the remaining items were meaningful to a given participant; for instance, it was not reasonable to ask a single person about divorce. Because no measure can include all possible experiences

\footnotetext{
${ }^{4}$ Considering the proposed construct of life experiences, which includes perceptions, some items can include a higher degree of subjectivity. 5 Traditionally, life event measures use binary responses (yes vs. no) to collect data about occurrence; nevertheless, during the development of LIFES, it was realized that a third option (do not remember) should also be available to include all natural responses.
} 
(e.g., Cleary, 1980), LIFES includes three blank spaces, where participants can add other relevant life experiences. According to this structure, the occurrence of lived experiences ranges from 0 to 78 . The instructions direct participants to complete the first question (occurrence) on all of the items; they then complete the remaining questions (i.e., developmental stage, valence, and impact) only if they chose the yes option for occurrence. Note that for each item, the participant can select one or more developmental stages $^{6}$; additionally, valence and impact can be rated separately for each developmental stage.

Despite the existence of alternative scoring options (depending on the purposes of the study), for the lived experiences section, we considered that combining valence and impact generate the most informative score since it includes both emotional tone and how much it affects the individual life, based on the participant's self-ratings.

The total positive lived experiences is obtained by counting the experiences with valence rated as positive and impact rated as some, quite, or absolutely. The same procedure is followed to obtain the total negative lived experiences (when valence is rated as negative) and the total neutral lived experiences (when valence is rated as neutral). Summing these totals (positive, negative, and neutral lived experiences) provides the total lived experiences. The mean positive lived experiences and the mean negative lived experiences are derived by dividing the appropriate total by the total lived experiences ${ }^{7}$.

In the non-lived experiences section, the participants are asked if they have any non-lived experience that was deeply desired (followed by the example of someone with an incurable disease who deeply desires the development of an effective treatment). If the participant answers negatively (no option), the section is complete; if the participant answers positively (yes option), they are directed to identify the non-lived experiences in blank spaces organized by developmental stage, i.e., childhood, adolescence, or adulthood. Additionally, the participant must rate the impact of each non-lived experience using the same question-and-answer scale applied to the lived experiences. The scoring consists of deriving the total non-lived experiences by summing the experiences reported in childhood, adolescence, and adulthood rated with some, quite, or absolute impact.

\section{EVIDENCES OF THE VALIDITY AND RELIABILITY}

\section{Specificities of life experience measures}

To avoid misconceptions about the analytical approach applied, before the presentation of evidence, it is important to clarify some particularities of life experience measures, which have a critical effect on their development and evaluation. Although psychological measures are traditionally rooted in the reflective model (e.g., Coltman, Devinney, Midgley, \& Venaik, 2008), life experience measures seem to be nested in the formative model (Bollen \& Bauldry, 2011). A detailed comparison between the models is beyond the scope of this manuscript - an explanation and exemplification can be found in Edwards and Bagozzi (2000) - but it is noteworthy to revisit some considerations of the framework proposed by Coltman et al. (2008). Theoretically, in a formative model items do not need to share a common theme; furthermore, according to Netland (2005), life experiences' categorization should be conceptual and they are not interchangeable. The absence of assumptions regarding item intercorrelation and the difficulties in measuring error are highlighted in Coltman et al. (2008) empirical considerations. Consequently, as claimed by other researchers (e.g., Hooper, Stockton, Krupnick, \& Green, 2011), traditional procedures that used to be essential when a new measure was developed and tested, such as internal reliability and factorial analysis, are not appropriate methods for measures of life experience.

Attending to these specificities, the process of gathering data about the validation and reliability of LIFES consisted of several steps and six empirical studies, the aims, methods, and results of which are described below. According to the standards for educational and psychological testing proposed by the American Educational Research Association (AERA), the American Psychological Association (APA), and the National Council on Measurement in Education (NCME, 2002), we present results from the evidence based on test content (Study 1), on response processes (Study 2), on relations to other variables (Study 3 ), and on reliability (Study 4).

\section{STUDY 1: EVIDENCE BASED ON TEST CONTENT}

A preliminary version of LIFES was evaluated by a panel of junior and senior experts $(N=9$, age ranging from 25 to 51,100\% female), from both practice and research fields, who worked with different target populations (children, adolescents or adults) in different areas (e.g., clinical, health, development, justice).

${ }^{6}$ The following reference periods were presented to participants in the instructions section: childhood (up to 12 years of age), adolescence (13-17 years of age), or adulthood (18 years of age and older).

${ }^{7}$ Although the neutral option is a major novelty and advantage of LIFES (participants are not forced to rate experiences as negative or positive), neutral lived experiences were not further analyzed because usually they were evaluated to have little or no impact. 
Individually, they were directed to evaluate the appropriateness (e.g., Do you agree that the items typify the construct under investigation?), representativeness (e.g., Attending to childhood/adolescent/adulthood, do you agree that the items are representative?), and clarity (e.g., Do you agree that the questions are clear?) of the items and questions on a dichotomous scale (yes vs. no) and blank spaces to justify disagreement. Then, an overview of individual feedback was shared and discussed between the researchers and the experts; overall, there was an agreement that the items and questions were appropriate, relevant, and clear. Nevertheless, some suggestions (e.g., rewording, inclusion/exclusion of items, and organization of domains) were integrated into the final version. This strategy constitutes an initial effort to explore validation because it allows the collection of information about content validity; nevertheless, this is the most rudimentary strategy, and it has no empirical category of validity (e.g., Cook \& Beckman, 2006).

\section{STUDY 2: EVIDENCE BASED ON RESPONSE PROCESSES}

To gather information about response processes (i.e., the meaning and interpretation of items, performance strategies, and responses to particular items) during the development of LIFES, several sessions that employed the thinking-aloud method and focus groups were implemented with different participants from the community (males and females differing in age, education, and marital status; the only inclusion criterion was being 18 years or older). Evidence based on response processes was generated from a circular process; specifically, the feedback obtained was included in advanced versions, which were rechecked (by the same and new participants) until we were confident that there was a "fit between the construct and the detailed nature of performance or response actually engaged in by examinees" (AERA, APA, \& NCME, 2002, p.12). This process resulted primarily in changes at the items level, i.e., the rewording and refinement of experiences through the inclusion of examples or boundaries (e.g., I retired, including due to incapability).

\section{STUDY 3: EVIDENCE BASED ON RELATIONS TO OTHER VARIABLES}

According to AERA, APA, and NCME (2002, p. 13), "analyses of the relationship of test scores to variables external to the test provide another important source of validity evidence". To gather data about this type of evidence, three empirical studies were conducted to investigate the relations between LIFES and other relevant variables, i.e., sociodemographic and clinical variables (Study 3.1), psychological symptoms (3.2), and comparable measures of life events (Study 3.3).

\section{Study 3.1: Convergent and discriminant evidence: Comparing groups}

Aims. This study was designed to collect convergent and discriminant evidence, exploring similarities and differences in LIFES scores across five sociodemographic variables (i.e., sex, age, marital status, education, and employment status) and one clinical variable (i.e., psychological distress).

Participants. The study included 350 individuals from the community ${ }^{8}$, most being female (76.6\%), ranging in age from 18 to 92 years $(M=35.49, S D=19.49)$. Regarding marital status, $59.0 \%$ were single, $29.8 \%$ were married or cohabiting, $7.2 \%$ were widowed, and the remaining $4 \%$ were divorced or separated. Participants tended to be well educated, considering that the majority had completed high school (46\%) or 37.3\% had a college degree; however, $11.4 \%$ had four or fewer years of schooling. Concerning employment status, $43.1 \%$ were employed, $38.0 \%$ were students, $11.7 \%$ were retired, $5.1 \%$ were unemployed, and $2 \%$ presented another status (e.g., homemaker). More than one-fourth of participants (28.5\%) presented clinical levels of psychological distress.

Measures and procedures. According to our aims, in addition to LIFES (described previously), two additional measures were administered, i.e., a sociodemographic questionnaire and the Brief Symptom Inventory (BSI; Derogatis, 1993; we used the Portuguese version by Canavarro, 2007). Sociodemographic variables were assessed in a specific questionnaire, which included questions about sex, age, marital status, education (corresponding to the highest level of school completed), and current employment status. BSI assesses the frequency of 53 symptoms, which can be grouped in nine psychological symptoms scales and three global indices. A detailed description of BSI is presented in Study 3.2. The current study relied only on the clinical cut-off for the Portuguese population, i.e., 1.7 on the positive symptom distress index, which distinguished individuals clinically distressed from those not distressed. The study was submitted and approved by the Institutional Review Board and the National Commission for Data

${ }^{8}$ Participants presented in Studies 3.2 and 4.1-4.3 are subsamples of this initial sample. 
Protection. Two inclusion criteria were established, i.e., age (at least 18 years) and ability to read and understand written contents. In this study, a multi-site recruitment was conducted to promote heterogeneity in sociodemographic characteristics; more specifically, individuals were recruited through schools, institutions, and an adult care day center. Individuals were personally invited to participate in a study about health and positive and negative life experiences and were informed in detail about the conditions (e.g., non-payment, confidentiality). Individuals who agreed to participate were requested to sign an informed consent before completing a demographic questionnaire, LIFES and BSI in a pencil-andpaper format. The data were collected individually or in small groups, and there were no cases of distress during the administration of the booklet.

Statistical analysis. The data were analyzed using descriptive and inferential tests, through the IBM Statistical Package of Social Sciences Software (IBM SPSS; version 20 for Windows). Because the assumptions of parametric data were not met, namely normality, non-parametric difference tests were performed to compare groups: Mann-Whitney tests were used to test differences between two groups (i.e., related to sex and psychological distress), and Kruskal-Wallis tests were applied when more than two groups were compared (i.e., in marital status, education, and employment status). To clarify the differences suggested by Kruskal-Wallis analyses, Mann-Whitney tests were used, and based on a Bonferroni correction, all effects were tested at a .0167 level of significance. Regarding age, a JonckheereTerpstra test was performed to test for trends.

Results. As displayed in Table 1, lived experiences did not differ based on sex or marital status, but they were significantly affected by education, employment status, age and psychological distress. To clarify these differences, Mann-Whitney analyses were computed, applying a Bonferroni correction. Regarding education, individuals who completed graduate education reported more experiences than those with a basic education, $U=2775.00, z=-3.04, p=.002$, and a high school education, $U=7901.00, z=-3.60, p<$ .001. Additionally, individuals with a basic education reported high values on negative experiences than individuals with a high school education, $U=3384.50, z=-3.16, p=.002$, and there were no significant differences in other group comparisons. Students and individuals with other employment status significantly differed in the negative experiences reported, $U=3295.00, z=-2.79, p=.005$, suggesting that students presented fewer negative experiences. Concerning age, Jonckheere's test revealed a significant trend in the data, suggesting that the number of experiences reported increased with age, $J=.17945, z=$ $1.68, r=.09$. Lastly, psychological distress did not differ in the total of lived experiences, but distressed individuals presented significantly fewer positive experiences and more negative experiences than nondistress individuals. In contrast, non-lived experiences were not significantly affected by any of the analyzed variables, except for education. To clarify the effect of education, Mann-Whitney tests were performed with a Bonferroni correction, and any comparison achieved statistical significance. However, it is noteworthy that older, less educated and non-distressed individuals presented the lowest mean ranks.

\section{Study 3.2: Relation between LIFES and psychological symptoms}

Aims. This study aimed to investigate the association between LIFES and a negative health variable, i.e., psychological symptoms, that has been widely investigated in this field of research. Based on previous studies (e.g., Silva \& Maia, 2008), although we used different measures to assess life experiences, we hypothesized that psychological symptoms were significantly associated with life experiences. We expected that individuals with a higher number of negative life experiences would report more psychological symptoms, and individuals with a higher number of positive life experiences would report fewer psychological symptoms.

Participants. This study relied on the same sample presented on Study 3.1; one participant did not answer BSI, resulting in a sample of 349. This exclusion did not significantly affect modal categories on sociodemographic characteristics, i.e., female (76.5\%), single (59.2\%), employed (43.0\%), high school education (43.6\%) and aged (in average) 35.51 years.

Materials and procedures. Participants completed LIFES (described above) and the BSI to assess psychological symptoms. BSI comprises nine symptom scales (i.e., somatization, obsessive-compulsion, interpersonal sensitivity, depression, anxiety, hostility, phobic anxiety, paranoid ideation, and psychoticism) and the following three global indices: the global severity index (GSI: an indicator of the overall psychological distress level), the positive symptom distress index (PSI: an indicator of the intensity of symptoms), and the positive symptom total (PST: the number of self-reported symptoms). 
This measure directs participants to evaluate the frequency of 53 psychological symptoms during the previous week. In Portugal, BSI is validated for both clinical and community populations (Canavarro, 2007) and its internal consistency, assessed through Cronbach's alpha, for the present sample was .96. Procedures applied were detailed described in Study 3.1.

Table 1. Difference Tests, Mean Ranks, and Median for Lived and Non-Lived Experiences, by Sex, Age, Marital Status, Education, Employment Status, and Psychological Distress

\begin{tabular}{|c|c|c|c|c|}
\hline \multirow{3}{*}{ Groups } & \multicolumn{3}{|c|}{ Lived experiences } & \multirow{3}{*}{$\begin{array}{l}\text { Nonlived experiences } \\
\text { Mean rank (Median) }\end{array}$} \\
\hline & Total & Positive & Negative & \\
\hline & Mean rank (Median) & Mean rank (Median) & Mean rank (Median) & \\
\hline Sex & $\begin{array}{c}U=10310.50, z=-.85 \\
p=.389\end{array}$ & $\begin{array}{c}U=10455.00, z=-.67 \\
p=.506\end{array}$ & $\begin{array}{c}U=9561.50, z=-1.79 \\
p=.074\end{array}$ & $\begin{array}{c}U=4752.00, z=-.45 \\
p=.684\end{array}$ \\
\hline $\begin{array}{l}\text { Males } \\
(n=82)\end{array}$ & $167.24(38)$ & $169.00(32)$ & $158.10(3)$ & $120.54(0)$ \\
\hline $\begin{array}{l}\text { Females } \\
(n=68)\end{array}$ & $178.03(39)$ & $174.49(33)$ & $80.82(4)$ & $124.26(0)$ \\
\hline Age & $\begin{array}{c}H(2)=8.03 \\
p=.018\end{array}$ & $\begin{array}{c}H(2)=3.37 \\
p=.186\end{array}$ & $\begin{array}{c}H(2)=4.95 \\
p=.084\end{array}$ & $\begin{array}{c}H(2)=4.70 \\
p=.095\end{array}$ \\
\hline $\begin{array}{l}18-24 \\
(n=149)\end{array}$ & $159.78(38)$ & $163.50(32)$ & $161.77(3)$ & $121.01(0)$ \\
\hline $\begin{array}{l}25-64 \\
(n=160)\end{array}$ & $191.02(41)$ & $184.49(34)$ & $181.03(4)$ & $129.83(0)$ \\
\hline $\begin{array}{l}\geq 65 \\
(n=39)\end{array}$ & $162.97(38)$ & $175.55(33)$ & $196.32(5)$ & $106.76(0)$ \\
\hline $\begin{array}{l}\text { Marital } \\
\text { status }\end{array}$ & $\begin{array}{c}H(2)=4.52 \\
p=.104\end{array}$ & $\begin{array}{c}H(2)=3.40 \\
p=.182\end{array}$ & $\begin{array}{c}H(2)=3.38 \\
p=.184\end{array}$ & $\begin{array}{c}H(2)=1.93 \\
p=.380\end{array}$ \\
\hline $\begin{array}{l}\text { Single } \\
(n=206)\end{array}$ & $165.68(38)$ & $167.96(32)$ & $167.71(4)$ & $122.39(0)$ \\
\hline $\begin{array}{l}\text { Married } \\
(n=104)\end{array}$ & $185.95(40)$ & $180.10(33)$ & $181.11(4)$ & $128.56(0)$ \\
\hline $\begin{array}{l}\text { Other } \\
(n=39)\end{array}$ & $195.00(40)$ & $198.58(35)$ & $197.21(5)$ & $112.57(0)$ \\
\hline Education & $\begin{array}{c}H(2)=15.77 \\
p<.001\end{array}$ & $\begin{array}{c}H(2)=1.86 \\
p=.394\end{array}$ & $\begin{array}{c}H(2)=10.27 \\
p=.006\end{array}$ & $\begin{array}{c}H(2)=6.04 \\
p=.049\end{array}$ \\
\hline $\begin{array}{l}\text { Basic } \\
(n=59)\end{array}$ & $156.57(38)$ & $164.03(31)$ & $210.58(5)$ & $105.03(0)$ \\
\hline $\begin{array}{l}\text { High school } \\
(n=159)\end{array}$ & $159.93(38)$ & $182.23(32)$ & $161.47(3)$ & $126.93(0)$ \\
\hline $\begin{array}{l}\text { Graduate } \\
(n=130)\end{array}$ & $203.38(42)$ & $169.80(35)$ & $174.06(4)$ & $129.03(0)$ \\
\hline $\begin{array}{l}\text { Employment } \\
\text { status }\end{array}$ & $\begin{array}{c}H(2)=2.82 \\
p=.244\end{array}$ & $\begin{array}{c}H(2)=1.91 \\
\quad p=.385\end{array}$ & $\begin{array}{c}H(2)=8.77 \\
p=.012\end{array}$ & $\begin{array}{c}H(2)=1.12 \\
p=.571\end{array}$ \\
\hline $\begin{array}{l}\text { Student } \\
(n=133)\end{array}$ & $167.83(38)$ & $181.92(32)$ & $158.47(3)$ & $123.34(0)$ \\
\hline $\begin{array}{l}\text { Employed } \\
(n=151)\end{array}$ & $185.92(40)$ & $173.89(33)$ & $175.96(4)$ & $126.94(0)$ \\
\hline $\begin{array}{l}\text { Other } \\
(n=66)\end{array}$ & $167.11(38)$ & $161.03(32)$ & $203.23(5)$ & $116.49(0)$ \\
\hline $\begin{array}{l}\text { Psychological } \\
\text { distress }\end{array}$ & $\begin{array}{c}U=10585.50, z=-.05, p \\
=.957\end{array}$ & $\begin{array}{c}U=8603.50, z=-2.57, p \\
=.010\end{array}$ & $\begin{array}{c}U=7386.50, z=-4.19, p \\
<.001\end{array}$ & $\begin{array}{c}U=5055.00, z=-.97 \\
p=.333\end{array}$ \\
\hline $\begin{array}{l}\text { Absence } \\
(n=231)\end{array}$ & $161.82(39)$ & $169.43(33)$ & $147.26(4)$ & $111.79(0)$ \\
\hline $\begin{array}{l}\text { Presence } \\
(n=92)\end{array}$ & $162.44(39)$ & $140.02(32)$ & $195.21(5)$ & $119.16(0)$ \\
\hline
\end{tabular}

Statistical analysis. Associations between the measures were calculated through Spearman's correlation because the variables were not normally distributed. The IBM Statistical Package for Social Sciences software (IBM SPSS; version 20 for Windows) was used for the data analysis.

Results. According to Table 2, the mean of positive lived experiences was negatively associated with symptom scales and global indices, suggesting that individuals who reported a higher number of positive lived experiences exhibited fewer psychological symptoms. Conversely, a mean of negative lived experiences was positively correlated with BSI, indicating that individuals with a higher number of negative lived experiences showed higher levels of psychological symptoms. Concerning non-lived 
experiences, only obsessive-compulsion and psychoticism presented significant correlations with LIFES, suggesting that participants with larger numbers of non-lived experiences reported higher levels of psychological symptoms.

Table 2. Spearman's Correlations Between LIFES and BSI.

\begin{tabular}{|c|c|c|c|c|}
\hline & \multicolumn{4}{|c|}{ LIFES } \\
\hline & \multicolumn{3}{|c|}{ Lived experiences } & \multirow{2}{*}{ Non-lived experiences } \\
\hline & Mean of positive & Mean of negative & Total & \\
\hline \multicolumn{5}{|l|}{ BSI } \\
\hline Somatisation & $-.21^{* * *}$ & $.28^{* * *}$ & .04 & .08 \\
\hline Obsessive-compulsion & $-.22^{* * *}$ & $.19^{* *}$ & .04 & $.15^{*}$ \\
\hline Interpersonal sensitivity & $-.25^{* * *}$ & $.25^{* * *}$ & .02 & .07 \\
\hline Depression & $-.32^{* * *}$ & $.33^{* * *}$ & -.01 & .08 \\
\hline Anxiety & $-.19^{* * *}$ & $.21^{* * *}$ & $.10^{+}$ & .09 \\
\hline Hostility & $-.20^{* * *}$ & $.20^{* * *}$ & .01 & .01 \\
\hline Phobic anxiety & $-.16^{* *}$ & $.16^{* *}$ & .04 & -.04 \\
\hline Paranoid ideation & $-.28^{* * *}$ & $.27^{* * *}$ & .01 & .07 \\
\hline Psychoticism & $-.24^{* * *}$ & $.20^{* * *}$ & -.06 & $.11^{*}$ \\
\hline GSI & $-.28^{* * *}$ & $.30^{* * *}$ & .05 & $.10^{+}$ \\
\hline PSI & $-.24^{* * *}$ & $.22^{* * *}$ & .03 & .09 \\
\hline PST & $-.22^{* * *}$ & $.32^{* * *}$ & -.01 & .05 \\
\hline
\end{tabular}

Note. GSI: overall psychological distress level; PSI: positive of symptoms; PST: the number of self-reported symptoms. ${ }^{+} p<.10{ }^{*} p<.05{ }^{* *} p<.01{ }^{* * *} p<.001$.

\section{Study 3.3: Convergent evidence: Comparing measures}

Aims. This study addressed convergent validity, a main procedure for the validation of a new measure, which consists of the comparison between a new measure and a well-validated questionnaire, assessing a similar construct (AERA, APA, \& NCME, 2002). Due to LIFES's specificities, there is no single similar measure available; therefore, it was compared with two distinct measures, one covering childhood/adolescence and another covering adulthood.

Participants. Of the 258 adults from the community who answered an online questionnaire, 24 were excluded due to the high number of missing answers, due to concerns about duplicated answers or because they represented outliers. Consequently, 234 participants were further analyzed. The mean age was 31.15 years $(S D=8.41, \min =18 ; \max =67), 74.4 \%$ were female, and most participants were single (63.5\%) or married/cohabitating (33.9\%). Regarding education, $46.1 \%$ reported completing graduate or undergraduate studies, $37.1 \%$ reported completing a technical course, and $13.4 \%$ reported completing secondary school. The majority were employed (60.6\%), $21.7 \%$ were students, and $10.4 \%$ were unemployed.

Materials and procedures. To analyze a comprehensive set of life experiences, we compared LIFES with two different and unrelated measures, that had been previously validated to our population, i.e., the ACE Study Questionnaire (ACE; Felitti et al. 1998, Portuguese version by Silva and Maia, 2008) to assess life experiences throughout childhood/adolescence, and the Life Experiences Survey (LES; Sarason et al., 1978; we used the Portuguese version by Pedro \& Pinto, 2013) to assess life experiences throughout adulthood. Attending to our aim, a careful selection of expectable matching items between LIFES and ACE or LES preceded the data collection; this selection was made by two independent researchers, resulting in19 pairs of common items ( 9 comparing LIFES/ACE and 10 comparing LIFES/LES) ${ }^{9}$. For LIFES items, participants were asked about the occurrence of specific life experiences and to specify the developmental stage of occurrence, using four answering options (no vs. yes, throughout childhood/adolescence vs. yes, throughout adulthood vs. yes, throughout childhood/adolescence and adulthood). For ACE and LES items, participants were instructed to answer only about the occurrence

${ }^{9}$ Some comparisons required collapsing items into singular categories (e.g., physical abuse). 
throughout childhood/adolescence and adulthood, respectively, using a dichotomized scale (no vs. yes). Some items required a more detailed comparison to guarantee a proper assessment; consequently, other variables (e.g., people involved, desirability) were also included. An e-mail invitation was sent to formal and informal networks, asking people aged 18 or older to participate in a study about life experiences. For those who were willing to collaborate informed consent was presented, preceding sociodemographic and life experiences questions. After data collection, to have meaningful comparisons, LIFES was recoded. Those items that were compared with ACE were converted into presence if the participant reported the experience throughout childhood/adolescence and into absence if the participant did not report the experience or if the participant reported that it happened throughout adulthood. The same conversion was applied to those items compared with LES, changing the occurrence's focus to adulthood.

Statistical analysis. To assess convergence between measures, the percentage of agreement and Cohen's kappa (Cohen, 1960) were computed for each item; the benchmarks suggested by Landis and Koch (1977) were used to interpret the results, i.e., poor $(<.00)$, slight $(.00-.20)$, fair $(.21-.40)$, moderate (.41$.60)$, substantial (.61-.80), and almost perfect (.81-1.00). For a global comparison, Pearson's correlations between LIFES and ACE and between LIFES and LES total scores were also computed. The IBM Statistical Package for Social Sciences software (IBM SPSS; version 20 for Windows) was used for data analysis.

Results. Overall, the comparison of LIFES and ACE presented a substantial kappa, $\kappa=.75, S E=.02,95 \%$ $\mathrm{CI}=[.72, .78]$, and $88.73 \%$ agreement for childhood/adolescence experiences. The two measures were significantly correlated, $r=.59, p<.001$. As shown in Table 3 , the kappa values for individual items ranged from fair to substantial and the percentages of agreement ranged from 72.65 to 94.85 . Concerning the comparison between LIFES and LES, the overall percentage of agreement was 93.01, and the Cohen's kappa was almost perfect, $\kappa=.81, S E=.02,95 \%$ CI $=[.78, .84]$. Additionally, LIFES and LES were positively correlated, $r=.83, p<.001$. Individual items from adulthood ranged from moderate to substantial values of kappa, and the percentage of agreement was above 80.

Table 3. Convergence of Comparable Items on the LIFES and ACE or LES-

\begin{tabular}{|c|c|c|c|c|c|c|c|c|c|}
\hline \multirow{2}{*}{ Life Experiences } & \multirow{2}{*}{$N$} & \multicolumn{4}{|c|}{ LIFES vs. ACE } & \multicolumn{4}{|c|}{ LIFES vs. LES } \\
\hline & & $\% \mathrm{Agr}$ & $\kappa$ & $S E$ & $95 \% \mathrm{CI}$ & \% Agr & $\kappa$ & $S E$ & 95\% CI \\
\hline Verbal violence & 234 & 72.6 & .45 & .06 & {$[.33, .56]$} & na & na & na & na \\
\hline Physical violence & 234 & 77.4 & .34 & .06 & {$[.21, .46]$} & na & na & na & na \\
\hline Interparental violence & 234 & 87.2 & .47 & .08 & {$[.31, .62]$} & na & na & na & na \\
\hline Sexual violence & 234 & 93.2 & .54 & .10 & {$[.34, .74]$} & na & na & na & na \\
\hline Care and protection & 234 & 93.6 & .37 & .13 & {$[.13, .62]$} & na & na & na & na \\
\hline Parental divorce or separation & 230 & 93.9 & .72 & -07 & {$[.58, .86]$} & na & na & na & na \\
\hline Love and affection by family & 234 & 94.0 & .39 & .13 & {$[.14, .64]$} & na & na & na & na \\
\hline Physical neglect (feeding) & 233 & 94.9 & .37 & .14 & {$[.09, .65]$} & na & na & na & na \\
\hline Rejection by family members & 200 & 92.5 & .25 & .13 & {$[-.01, .51]$} & na & na & na & na \\
\hline House changing & 231 & na & na & na & na & 81 & .56 & .06 & {$[.45, .67]$} \\
\hline Death of a close one & 231 & na & na & na & na & 85.3 & .66 & .06 & {$[.56, .76]$} \\
\hline Physical or mental illness & 231 & na & na & na & na & 84.9 & .57 & .06 & {$[.45, .70]$} \\
\hline Marriage/cohabitating & 232 & na & na & na & na & 90.5 & .79 & .04 & {$[.71, .87]$} \\
\hline Divorce or separation & 230 & na & na & na & na & 94.8 & .58 & .11 & {$[.36, .79]$} \\
\hline Pregnancy & 232 & na & na & na & na & 97.4 & .93 & .03 & {$[.87, .98]$} \\
\hline Son/daughter left home & 230 & na & na & na & na & 97.8 & .70 & .13 & {$[.44, .95]$} \\
\hline Abortion & 231 & na & na & na & na & 98.7 & .90 & .06 & {$[.79,1]$} \\
\hline Detention & 226 & na & na & na & na & 100 & a & a & a \\
\hline Retirement & 228 & na & na & na & na & 100 & 1 & .00 & {$[1,1]$} \\
\hline
\end{tabular}

Note. $\%$ Agre = percentage of agreement. $\kappa=$ Cohen's kappa. $S E=$ standard error. $\mathrm{CI}=$ confidence interval. na $=$ not applicable.

aNo statistics were computed because the variable was a constant. 


\section{STUDY 4: EVIDENCE BASED ON RELIABILITY}

According to APA (2016, based on Gerrig and Zimbardo, 2002), reliability refers to "the degree to which a test produces similar scores each time it is used; stability or consistency of the scores produced by an instrument". It is usually presented as internal consistency (through Cronbach's alpha). Due to the specificities described above, item intercorrelation is not expectable in LIFES; consequently, internal consistency is not a suitable parameter to compute. Instead, three alternative classes of reliability were estimated, (i.e., temporal, cross-method and inter-rater reliability), the aims, participants, procedures and results of which will be detailed described below. To avoid unnecessary repetition, it should be noted that in general, the data and statistical analyses applied were the same: Data were analyzed using the IBM Statistical Package for Social Sciences Software (IBM SPSS; version 20 for Windows) and Excel for Windows. Cohen's kappa (Cohen, 1960), standard errors, confidence intervals, and the percentage of agreement were calculated by individual items, by domains, and as whole (overall reliability). To interpret Cohen's kappa, Landis and Koch (1977) proposed the following benchmarks: poor (<.00), slight $(.00-.20)$, fair (.21-.40), moderate (.41-.60), substantial (.61-.80), and almost perfect (.81-1.00).

\section{Study 4.1: Temporal reliability}

Aims. This study was designed to assess the temporal reliability of LIFES using a test-retest design, i.e., the same individuals were assessed twice with the same measure and under the same conditions.

Participants. Temporal reliability was analyzed based on responses from 78 individuals from the community. The mean age at initial assessment was 29.21 years $(S D=12.95$, range $=18-61)$, and $87.2 \%$ of participants were female. The majority was single $(65.4 \%)$ or married $(30.8 \%)$; only $2.6 \%$ and $1.3 \%$ reported being divorced or widowed, respectively. Globally, participants were well educated: $92.2 \%$ had completed high school education; of those, $32 \%$ had a college degree. At the time of data collection, most participants were students (59\%), 39.7\% were employed, and 1.3\% were unemployed.

Procedures. After institutional approvals were obtained, individuals ${ }^{10}$ were invited to collaborate in a two-phase study about life experiences and health. Informed written consent was obtained for all participants during the first data collection (T1). To assess temporal reliability, LIFES (described above) was administered on two different occasions; the mean elapsed time between the test and retest was 154.58 days $(S D=121.57)$. Although they were aware of the second data collection (T2), participants were not informed that LIFES would be applied twice. Participants answered LIFES using a self-report method, individually or in small groups to guarantee privacy and were asked to mark differently "new experiences" (those that happened between T1 and T2). In addition to the statistical analyses mentioned previously, Pearson's correlations were computed to analyze the associations between the total numbers of lived and non-lived experiences reported in the test and retest.

Results. Regarding lived experiences, according to the benchmarks proposed by Landis and Koch (1977), the overall kappa of LIFES was almost perfect, $\kappa=.82, S E=.01,95 \% \mathrm{CI}=[.80, .83]$, 90.59\% agreement. Additionally, there was a significant Pearson's correlation between the lived experiences reported at T1 and T2 $(r=.82, p<.001)$, suggesting that participants who reported a higher number of life experiences in the test also reported a higher number of life experiences in the retest. At the domain level, an almost perfect kappa was also presented by school, $\kappa=.90, S E=.02,95 \% \mathrm{CI}=[.86, .93], 94.80 \%$ of agreements; job, $\kappa=.81, S E=.04,95 \% \mathrm{CI}=[.73, .89], 91.04 \%$ agreement; health, $\kappa=.85, S E=.03,95 \% \mathrm{CI}=[.80, .91]$, $92.55 \%$ agreement; life conditions, $\kappa=.86, S E=.02,95 \% \mathrm{CI}=[.81, .90], 92.93 \%$ agreement; and people and relationships, $\kappa=.82, S E=.01,95 \% \mathrm{CI}=[.80, .85], 90.76 \%$ agreement. Leisure and adverse experiences presented a substantial kappa, $\kappa=.67, S E=.04,95 \% \mathrm{CI}=[.60, .74], 84.75 \%$ agreement and $\kappa$ $=.63, S E=.08,95 \% \mathrm{CI}=[.47, .79], 95.47 \%$ agreement, respectively. A moderate kappa was achieved by accomplishments, $\kappa=.57, S E=.04,95 \% \mathrm{CI}=[.49, .66], 77.67 \%$ agreement. Agreement parameters for individual items are shown in Table 4.

\footnotetext{
${ }_{10}$ Participants from Studies 4.1 and 4.2 were recruited in the same data collection and were randomly allocated at one of the conditions at T2.
} 
Table 4. Temporal, Cross-Methods, and Inter-Rater Reliability for Individual Items.

\begin{tabular}{|c|c|c|c|c|c|c|c|c|c|c|c|c|c|c|c|}
\hline \multirow{3}{*}{ Items } & \multicolumn{15}{|c|}{ Reliability } \\
\hline & \multicolumn{5}{|c|}{ Temporal } & \multicolumn{5}{|c|}{ Cross-Methods } & \multicolumn{5}{|c|}{ Inter-rater } \\
\hline & $N$ & $\begin{array}{c}\% \\
\text { Agre }\end{array}$ & $\kappa$ & $S E$ & $95 \% \mathrm{CI}$ & $N$ & $\begin{array}{l}\% \\
\text { Agre }\end{array}$ & $\kappa$ & $S E$ & $95 \% \mathrm{CI}$ & $N$ & $\begin{array}{l}\text { \% } \\
\text { Agre }\end{array}$ & $\kappa$ & $S E$ & $95 \% \mathrm{CI}$ \\
\hline \multicolumn{16}{|l|}{ School } \\
\hline 1. I began elementary school. ${ }^{b}$ & 78 & 98.7 & a & a & a & 62 & 100 & a & a & a & 84 & 100 & a & a & a \\
\hline $\begin{array}{l}\text { 2. I changed schools due to progress of } \\
\text { academic level. }\end{array}$ & 75 & 88 & .24 & .18 & {$[-0.10, .59]$} & 59 & 89.8 & .45 & .19 & {$[.07, .82]$} & 82 & 90.2 & .59 & .13 & {$[.33, .84]$} \\
\hline 3. I changed schools at the same academic level. & 68 & 91.2 & .41 & .15 & {$[.13, .70]$} & 50 & 78.0 & .41 & .15 & {$[.13, .70]$} & 80 & 88.8 & .60 & .12 & {$[.37, .83]$} \\
\hline $\begin{array}{l}\text { 4. I began a professional program or university } \\
\text { degree. }^{\text {b }}\end{array}$ & 62 & 100 & 1 & 0 & [1] & 50 & 98.0 & .85 & .15 & {$[.55,1.14]$} & 83 & 96.4 & .85 & .09 & {$[.68,1.02]$} \\
\hline $\begin{array}{l}\text { 5. I finished a professional program or } \\
\text { university degree. }\end{array}$ & 62 & 93.5 & .86 & .07 & {$[.73, .99]$} & 44 & 93.2 & .86 & .08 & {$[.71,1.01]$} & 76 & 96.1 & .92 & .05 & {$[.83,1.01]$} \\
\hline 6. I failed a school year. & 75 & 93.3 & .79 & .09 & {$[.61, .97]$} & 56 & 98.2 & .96 & .04 & {$[.88,1.04]$} & 83 & 95.2 & .88 & .06 & {$[.77, .99]$} \\
\hline 7. I abandoned school. & 70 & 97.1 & .84 & .11 & {$[.63,1.06]$} & 52 & 86.5 & .55 & .15 & {$[.26, .84]$} & 83 & 98.8 & .93 & .07 & {$[.78,1.07]$} \\
\hline 8. I was expelled from school. & 68 & 97.1 & -.02 & .01 & {$[-.04, .01]$} & 49 & 100.0 & 1 & 0 & [1] & 83 & 100 & a & a & a \\
\hline \multicolumn{16}{|l|}{ Job } \\
\hline 9. I have some work experience. & 77 & 89.6 & .75 & .08 & {$[.59, .91]$} & 58 & 84.5 & .57 & .13 & {$[.32, .82]$} & 84 & 95.2 & .88 & .06 & {$[.77, .99]$} \\
\hline 10. I became unemployed. & 41 & 95.1 & .86 & .10 & {$[.67,1.05]$} & 32 & 84.4 & .66 & .14 & {$[.39, .93]$} & 59 & 84.7 & 69 & .09 & {$[.51, .88]$} \\
\hline 11. I was promoted. & 41 & 80.5 & .55 & .14 & {$[.28, .81]$} & 35 & 88.6 & .77 & .10 & {$[.57, .98]$} & 54 & 94.4 & .86 & .08 & {$[.72,1.01]$} \\
\hline 12. I retired. & 42 & 100 & a & a & a & 29 & 100 & 1 & 0 & [1] & 58 & 100 & a & a & a \\
\hline \multicolumn{16}{|l|}{ Health } \\
\hline 13. Most of the time I felt healthy. & 75 & 93.3 & .42 & .20 & {$[.02, .82]$} & 61 & 83.6 & .24 & .14 & {$[-.04, .52]$} & na & na & na & na & na \\
\hline 14. I was admitted to the hospital. & 76 & 85.5 & .72 & .08 & $(.58, .87]$ & 57 & 91.2 & .81 & .08 & {$[.66, .97]$} & 83 & 86.7 & .73 & .08 & {$[.59, .88]$} \\
\hline 15. I had a psychiatric disease. ${ }^{b}$ & 62 & 96.8 & .91 & .06 & {$[.79,1.03]$} & 47 & 83.0 & .53 & .14 & {$[.25, .81]$} & 84 & 94 & .51 & .19 & {$[.14, .89]$} \\
\hline 16. I recovered from a psychiatric disease. & 14 & 78.6 & -.08 & .06 & {$[-.19, .04]$} & 5 & 100 & a & a & a & 2 & 50 & a & a & a \\
\hline 17. I had a serious physical disease/problem. ${ }^{\mathrm{b}}$ & 59 & 89.8 & .64 & .13 & {$[.38, .90]$} & 43 & 90.7 & .74 & .12 & {$[.50, .98]$} & 84 & 90.5 & .64 & .12 & {$[.40, .87]$} \\
\hline $\begin{array}{l}\text { 18. I recovered from a serious physical } \\
\text { disease/problem. }\end{array}$ & 7 & 100 & a & a & a & 8 & 87.5 & a & a & a & 9 & 88.9 & .61 & .34 & {$[-.06,1.28]$} \\
\hline 19. I became pregnant. $\mathrm{b}$ & 64 & 100 & 1 & 0 & {$[1]$} & 53 & 94.3 & .89 & .06 & {$[.76,1.01]$} & 84 & 100 & 1 & 0 & [1] \\
\hline 20. I had an abortion. & 19 & 94.7 & .89 & .10 & {$[.69,1.10]$} & 21 & 90.5 & .80 & .14 & {$[.53,1.06]$} & 12 & 100 & 1 & 0 & [1] \\
\hline
\end{tabular}


Table 4. Temporal, Cross-Methods, and Inter-Rater Reliability for Individual Items. (Cont.)

\begin{tabular}{|c|c|c|c|c|c|c|c|c|c|c|c|c|c|c|c|}
\hline & \multicolumn{5}{|c|}{ Temporal } & \multicolumn{5}{|c|}{ Cross-Methods } & \multicolumn{5}{|c|}{ Inter-rater } \\
\hline & $N$ & $\begin{array}{c}\% \\
\text { Agre }\end{array}$ & $\kappa$ & $S E$ & $95 \% \mathrm{CI}$ & $N$ & $\begin{array}{c}\% \\
\text { Agre }\end{array}$ & $\kappa$ & $S E$ & $95 \% \mathrm{CI}$ & $N$ & $\begin{array}{c}\% \\
\text { Agre }\end{array}$ & $\kappa$ & $S E$ & $95 \% \mathrm{CI}$ \\
\hline \multicolumn{16}{|l|}{ Leisure } \\
\hline 21. I belonged to a sport team. & 76 & 88.2 & .76 & .07 & {$[.61, .91]$} & 61 & 82 & .65 & .10 & {$[.46, .83]$} & 83 & 91.6 & .83 & .61 & {$[-.36,2.03]$} \\
\hline 22. I belonged to religious group. & 77 & 81.8 & .63 & .09 & {$[.46, .81]$} & 60 & 88.3 & .77 & .08 & {$[.60, .93]$} & 82 & 84.1 & .68 & .82 & {$[-.93,2.28]$} \\
\hline 23. I belonged to a recreational/cultural group. & 76 & 88.2 & .75 & .08 & {$[.60, .90]$} & 58 & 86.2 & .73 & .09 & {$[.56, .90]$} & 82 & 89 & .70 & .94 & {$[1.15,2.54]$} \\
\hline $\begin{array}{l}\text { 24. Most of the time, I had leisure time, having } \\
\text { fun with myself. }\end{array}$ & 76 & 71.1 & .47 & .09 & {$[.30, .64]$} & 60 & 55 & .18 & .09 & {$[0, .36]$} & na & na & na & na & na \\
\hline $\begin{array}{l}\text { 25. Most of the time, I had leisure time, having } \\
\text { fun with my family. }\end{array}$ & 77 & 87 & .41 & .15 & {$[.12, .70]$} & 61 & 91.8 & .25 & .23 & {$[-.20, .70]$} & na & na & na & na & na \\
\hline $\begin{array}{l}\text { 26. Most of the time, I had leisure time, having } \\
\text { fun with my friends/colleagues. }\end{array}$ & 77 & 92.2 & .22 & .21 & {$[-.19, .62]$} & 62 & 96.8 & -.02 & .01 & {$[-.04, .01]$} & na & na & na & na & na \\
\hline \multicolumn{16}{|l|}{ Life conditions } \\
\hline $\begin{array}{l}\text { 27. Most of the time, the food available for my } \\
\text { meals was insufficient. }\end{array}$ & 76 & 89.5 & .23 & .16 & {$[-.08, .54]$} & 62 & 95.2 & .75 & .14 & {$[.48,1.02]$} & 83 & 95.2 & .58 & .19 & {$[.20, .95]$} \\
\hline 28. I changed residences. & 76 & 93.4 & .79 & .09 & {$[.61, .97]$} & 62 & 93.5 & .70 & .13 & {$[-.44, .96]$} & 84 & 98.8 & .98 & .02 & {$[.93,1.02]$} \\
\hline $\begin{array}{l}\text { 29. Most of the time, I felt safe in the place } \\
\text { where I lived. }\end{array}$ & 73 & 87.7 & .31 & .15 & {$[.02, .60]$} & 62 & 95.2 & .55 & .23 & {$[.09,1]$} & na & na & na & na & na \\
\hline 30. I became economically independent. & 76 & 96.1 & .92 & .05 & {$[.83,1.01]$} & 62 & 96.8 & .93 & .05 & {$[.84,1.02]$} & 84 & 96.4 & .93 & .04 & {$[.85,1.01]$} \\
\hline 31. I bought/received my own house. & 75 & 96 & .91 & .05 & $(.81,1.01]$ & 61 & 95.1 & .90 & .06 & {$[.79,1.01]$} & 84 & 97.6 & .92 & .06 & {$[.81,1.03]$} \\
\hline 32. I bought/received a vehicle. & 74 & 90.5 & .81 & .07 & {$[.68, .94]$} & 60 & 100.0 & 1 & 0 & {$[1]$} & 84 & 95.2 & .91 & .05 & {$[.81,1]$} \\
\hline 33. I lost my house or my belongings. & 73 & 97.3 & -.01 & .01 & {$[-.03, .01]$} & 59 & 94.9 & -.02 & .02 & {$[-.05, .01]$} & 84 & 100 & 1 & 0 & [1] \\
\hline \multicolumn{16}{|l|}{ Adverse experiences } \\
\hline $\begin{array}{l}\text { 34. I was involved in a serious accident with a } \\
\text { vehicle. }\end{array}$ & 75 & 92 & .66 & .13 & {$[.41, .91]$} & 61 & 85.2 & .45 & .15 & {$[.15, .74]$} & 81 & 95.1 & 0.64 & 0.17 & {$[.31, .97]$} \\
\hline 35. I was involved in a fire. & 75 & 100 & 1 & 0 & {$[1]$} & 61 & 88.5 & .25 & .17 & {$[-.08, .58]$} & 83 & 97.6 & .79 & .15 & {$[.50,1.07]$} \\
\hline 36. I was involved in a robbery. & 76 & 88.2 & .41 & .16 & {$[.10, .72]$} & 60 & 93.3 & .74 & .12 & {$[.50, .98]$} & 83 & 94 & .70 & .13 & {$[.46, .95]$} \\
\hline 37. I was involved in a crime. & 74 & 97.3 & -.01 & .01 & {$[-.03, .01]$} & 61 & 93.4 & -.02 & .02 & {$[-.05, .01]$} & 83 & 100 & 1 & 0 & {$[1]$} \\
\hline 38. I was arrested. & 75 & 100 & a & a & a & 61 & 100 & a & a & a & 83 & 100 & a & a & a \\
\hline \multicolumn{16}{|l|}{ Accomplishments } \\
\hline $\begin{array}{l}\text { 39. I earned a prize or I was recognized for } \\
\text { something that I did. }\end{array}$ & 74 & 78.4 & .57 & .09 & {$[.40, .75]$} & 59 & 79.7 & .60 & .10 & {$[-.41, .80]$} & 76 & 85.5 & .71 & .08 & {$[.55, .87]$} \\
\hline
\end{tabular}


Table 4. Temporal, Cross-Methods, and Inter-Rater Reliability for Individual Items. (Cont.)

\begin{tabular}{|c|c|c|c|c|c|c|c|c|c|c|c|c|c|c|c|}
\hline & \multicolumn{5}{|c|}{ Temporal } & \multicolumn{5}{|c|}{ Cross-Methods } & \multicolumn{5}{|c|}{ Inter-rater } \\
\hline & $N$ & $\begin{array}{c}\% \\
\text { Agre }\end{array}$ & $\kappa$ & $S E$ & $95 \%$ CI & $N$ & $\begin{array}{c}\% \\
\text { Agre }\end{array}$ & $\kappa$ & $S E$ & $95 \%$ CI & $N$ & $\begin{array}{c}\% \\
\text { Agre }\end{array}$ & $\kappa$ & $S E$ & $95 \%$ CI \\
\hline $\begin{array}{l}\text { 40. I made a journey or visited a place that I } \\
\text { really wanted to see. }\end{array}$ & 75 & 84 & .66 & .09 & {$[.50, .83]$} & 61 & 78.7 & .52 & .11 & {$[.31, .72]$} & na & na & na & na & na \\
\hline $\begin{array}{l}\text { 41. I accomplished a project/ fulfilled a dream } \\
\text { that I really wanted. }\end{array}$ & 76 & 69.7 & .48 & .09 & {$[.31, .64]$} & 60 & 60 & .19 & .11 & {$[-.03, .41]$} & na & na & na & na & na \\
\hline $\begin{array}{l}\text { 42. I felt I was contributing to a better world/I } \\
\text { am proud of my legacy. }\end{array}$ & 75 & 78.7 & .56 & .09 & {$[.38, .74]$} & 61 & 73.8 & .12 & .11 & {$[-.10, .34]$} & na & na & na & na & na \\
\hline \multicolumn{16}{|l|}{ People and relationships } \\
\hline 43. I knew about my parents' relationship. ${ }^{b}$ & 77 & 89.6 & .37 & .18 & {$[.03, .72]$} & 61 & 90.2 & .35 & .21 & {$[-.05, .75]$} & 38 & 100 & 1 & 0 & [1] \\
\hline 44. My parents divorced. & 65 & 100 & 1 & 0 & {$[1]$} & 53 & 98.1 & .79 & .20 & {$[.39,1.19]$} & 40 & 100 & 1 & 0 & [1] \\
\hline 45. My parents used to shout at each other. & 65 & 90.8 & .81 & .07 & {$[.68, .95]$} & 51 & 68.6 & .36 & .12 & {$[.12, .60]$} & 39 & 97.4 & .94 & .06 & {$[.82,1.06]$} \\
\hline $\begin{array}{l}\text { 46. My parents used to physically attack each } \\
\text { other. }\end{array}$ & 65 & 93.8 & .69 & .15 & {$[.40, .97]$} & 53 & 94.3 & .64 & .19 & {$[.26,1.01]$} & 39 & 97.4 & .66 & .32 & {$[.03,1.28]$} \\
\hline 47. My parents used to insult each other. & 65 & 86.2 & .67 & .10 & {$[.48, .86]$} & 52 & 92.3 & .75 & .12 & {$[.52, .98]$} & 39 & 94.9 & .83 & .12 & {$[.60,1.06]$} \\
\hline $\begin{array}{l}\text { 48. My parents used to be physically } \\
\text { affectionate with each other. }\end{array}$ & 65 & 80 & .60 & .10 & {$[.41, .78]$} & 52 & 73.1 & .49 & .11 & {$[.28, .70]$} & 30 & 93.3 & .85 & .10 & {$[.65,1.05]$} \\
\hline $\begin{array}{l}\text { 49. My parents used to exchange words of } \\
\text { affection. }\end{array}$ & 65 & 73.8 & .56 & .09 & {$[.38, .74]$} & 52 & 65.4 & .43 & .09 & {$[.25, .60]$} & 27 & 92.6 & .85 & .10 & {$[.64,1.05]$} \\
\hline 50. I was involved in an intimate relationship. ${ }^{b}$ & 76 & 97.4 & .87 & .09 & {$[.70,1.04]$} & 60 & 95 & .74 & .14 & {$[.46,1.02]$} & 84 & 94 & .82 & .08 & {$[.67, .97]$} \\
\hline 51. I got married or lived in cohabitation. ${ }^{\mathrm{b}}$ & 53 & 98.1 & .96 & .04 & {$[.88,1.04]$} & 45 & 97.8 & .95 & .05 & {$[.85,1.05]$} & 84 & 100 & 1 & 0 & {$[1]$} \\
\hline 52. I divorced or separated. & 15 & 93.3 & .82 & .18 & {$[.47,1.16]$} & 27 & 100 & 1 & 0 & {$[1]$} & 17 & 94.1 & .85 & .14 & {$[.57,1.13]$} \\
\hline 53. I had a child. ${ }^{\mathrm{b}}$ & 70 & 97.1 & .94 & .04 & {$[.85,1.02]$} & 58 & 100 & 1 & 0 & [1] & 83 & 100 & 1 & 0 & [1] \\
\hline 54. I wished to have a child of a different sex. & 21 & 90.5 & .80 & .13 & {$[.54,1.06]$} & 29 & 96.6 & .87 & .13 & {$[.62,1.12]$} & na & na & na & na & na \\
\hline 55. I was forced to leave my child. & 23 & 100 & a & a & a & 32 & 100 & a & a & a & 12 & 100 & a & a & a \\
\hline $\begin{array}{l}\text { 56. My child had a serious disease or had severe } \\
\text { incapability. }\end{array}$ & 23 & 95.7 & a & a & a & 32 & 100 & a & a & a & 12 & 100 & a & a & a \\
\hline 57. I lived or had contact with my child. ${ }^{\mathrm{b}}$ & 22 & 95.5 & a & a & a & 32 & 96.9 & a & a & a & 10 & 100 & a & a & a \\
\hline $\begin{array}{l}\text { 58. Most of the time, I felt I did not know what } \\
\text { to do regarding my child. }\end{array}$ & 22 & 68.2 & -.15 & .08 & {$[-.31, .01]$} & 30 & 63.3 & .06 & .14 & {$[-.21, .33]$} & na & na & na & na & na \\
\hline $\begin{array}{l}\text { 59. Most of the time, I experienced pleasure } \\
\text { when taking care of my child. }\end{array}$ & 20 & 90 & -.05 & .04 & {$[-.13, .02]$} & 27 & 96.3 & a & a & a & na & na & na & na & na \\
\hline 60. My child left home for the first time. & 12 & 91.7 & .75 & .23 & {$[.30,1.20]$} & 23 & 87.0 & .50 & .25 & {$[.01, .99]$} & 11 & 100 & a & $\mathrm{a}$ & a \\
\hline $\begin{array}{l}\text { 61. My child returned home after prolonged } \\
\text { absence. }\end{array}$ & 2 & 50 & a & a & a & 4 & 25.0 & -.50 & .38 & {$[-1.24, .24]$} & 1 & 100 & $\mathrm{a}$ & a & a \\
\hline
\end{tabular}


Table 4. Temporal, Cross-Methods, and Inter-Rater Reliability for Individual Items. (Cont.)

\begin{tabular}{|c|c|c|c|c|c|c|c|c|c|c|c|c|c|c|c|}
\hline & \multicolumn{5}{|c|}{ Temporal } & \multicolumn{5}{|c|}{ Cross-Methods } & \multicolumn{5}{|c|}{ Inter-rater } \\
\hline & $N$ & $\begin{array}{c}\% \\
\text { Agre }\end{array}$ & $\kappa$ & & $N$ & $\begin{array}{c}\% \\
\text { Agre }\end{array}$ & $\kappa$ & & $N$ & $\%$ Agre & $\boldsymbol{K}$ & & $N$ & $\begin{array}{c}\% \\
\text { Agre }\end{array}$ & $\kappa$ \\
\hline 62. Most of the time, I felt I was a good father. & 22 & 95.5 & a & a & a & 30 & 86.7 & -.07 & .04 & {$[-.14,0]$} & na & na & na & na & $\mathrm{Na}$ \\
\hline 63. I was forced to leave my family. & 77 & 96.1 & .55 & .23 & {$[.10,1]$} & 57 & 94.7 & -.02 & .02 & {$[-.06, .01]$} & 84 & 97.6 & -.01 & .01 & {$[-.03, .01]$} \\
\hline 64. I had a pet.b & 64 & 93.8 & .74 & .12 & {$[.50, .98]$} & 52 & 82.7 & .53 & .14 & {$[.26, .80]$} & 84 & 96.4 & .89 & .06 & {$[.77,1.01]$} \\
\hline 65. I lost a pet. & 53 & 90.6 & .65 & .14 & {$[.38, .93]$} & 39 & 89.7 & .61 & .17 & {$[.27, .95]$} & 67 & 95.5 & .70 & .16 & {$[.39,1.02]$} \\
\hline 66. I did volunteer work. & 75 & 84 & .69 & .08 & {$[.54, .85]$} & 61 & 88.5 & .77 & .08 & {$[.61, .93]$} & 78 & 91 & .82 & .07 & {$[.69, .95]$} \\
\hline $\begin{array}{l}\text { 67. I was slapped, spanked, kicked or otherwise } \\
\text { physically attacked, leaving me with marks. }\end{array}$ & 77 & 87 & .43 & .15 & {$[.15, .72]$} & 62 & 90.3 & .52 & .17 & {$[.18, .85]$} & 84 & 88.1 & .51 & .13 & {$[.25, .78]$} \\
\hline 68. I felt loved and cherished. & 78 & 97.4 & -.01 & .01 & {$[-.02,0]$} & 60 & 100 & a & a & a & na & na & na & na & na \\
\hline $\begin{array}{l}\text { 69. Someone made fun of me and insulted me in } \\
\text { a way that hurt me. }\end{array}$ & 77 & 80.5 & .63 & .09 & {$[.46, .79]$} & 61 & 78.7 & .57 & .10 & {$[.37, .77]$} & na & na & na & na & na \\
\hline $\begin{array}{l}\text { 70. Besides greeting situations, I received } \\
\text { kisses. hugs and endearments. }\end{array}$ & 76 & 94.7 & .18 & .14 & {$[-.09, .46]$} & 60 & 91.7 & -.03 & .02 & {$[-.07,0]$} & 84 & 97.6 & .74 & .18 & {$[.39,1.09]$} \\
\hline 71. I felt supported in my important decisions. & 76 & 96.1 & .65 & .19 & {$[.28,1.02]$} & 60 & 91.7 & -.04 & .02 & {$[-.08,0]$} & na & na & na & na & na \\
\hline $\begin{array}{l}\text { 72. I felt that someone cared about me and } \\
\text { about my well-being. }\end{array}$ & 77 & 98.7 & .75 & .18 & {$[.39,1.10]$} & 58 & 100 & a & a & a & na & na & na & na & na \\
\hline 73. I had any unwanted sexual contact. & 76 & 93.4 & .63 & .15 & {$[.34, .93]$} & 62 & 93.5 & .57 & .19 & {$[.19, .94]$} & 84 & 90.5 & .51 & .15 & {$[.22, .80]$} \\
\hline 74. I felt someone hated me. & 76 & 76.3 & .53 & .09 & {$[.35, .71]$} & 62 & 74.2 & .34 & .12 & {$[.10, .58]$} & na & na & na & na & na \\
\hline 75. Someone important to me died. & 78 & 92.3 & .68 & .12 & {$[.44, .92]$} & 60 & 88.3 & .62 & .13 & {$[.37, .88]$} & na & na & na & na & na \\
\hline
\end{tabular}

Note. \% Agre = percentage of agreement. $K=$ Cohen's kappa. $S E=$ standard error. $\mathrm{CI}=$ confidence interval. na $=$ not applicable.

${ }^{a}$ No statistics were computed because the variable was a constant or the crosstabs were empty.

${ }^{\mathrm{b}}$ Contingency item. 
Regarding the occurrence of non-lived experiences, the percentage of agreement was 82 and Cohen's kappa was substantial for temporal reliability, $\kappa=.62, S E=.09,95 \%$ CI $=[.44, .81]$. Specifically, $51.4 \%$ of participants did not report non-lived experiences at either assessment, 30.6\% reported nonlived experiences at both assessments, $11.1 \%$ did not report at T1 but reported at T2, and $6.9 \%$ reported at T1 but not at T2. The mean of non-lived experiences was .60 $(S D=1.20$, range $=0-5)$ at T1 and .73 (SD $=1.22$; range $=0-6$ ) at T2; the Pearson's correlation between the number of non-lived experiences reported at T1 and T2 was significant, $r=.69, p<.001$.

\section{Study 4.2: Cross-method reliability}

Aims. This study was designed to assess the cross-method reliability of LIFES using again a test-retest design to evaluate whether reports were consistent when the same individuals were assessed twice under different conditions, i.e., comparing a self-report condition with an interview condition.

Participants. Cross-method reliability was analyzed based on responses from 69 participants, who were recruited from the community. At $\mathrm{T} 1$, the mean age was 38.61 years $(S D=14.27$, range $=18-64)$, and $77.4 \%$ were female. Regarding marital status, 50\% were married, $43.5 \%$ were single, $4.8 \%$ were divorced, and $1.6 \%$ were widowed. Most participants had a high school education (40.3\%) or a college degree (51.6\%); the remaining $8 \%$ had a basic education. Additionally, $58.1 \%$ of participants were employed, $35.5 \%$ were students, $3.2 \%$ reported being retired, and $3.2 \%$ presented another employment status.

Procedures. Similar procedures of those described in Study 4.1 were applied, with a major distinction: At T1 participants answered LIFES using a self-report method, but at T2, participants were face-to-face interviewed. All interviews were conducted by trained interviewers, who were blind to the results from T1. Again, although aware of the second data collection, participants were not informed that LIFES would be applied twice or that it would be applied using an interview inquiry. The mean elapsed time between the self-report condition and interview condition was 199.26 days $(S D=103.82)$. Similarly to Study 4.1 , agreement measures and Pearson's correlations were computed.

Results. Table 4 presents the agreement parameters for individual items on lived experiences. Concerning cross-method reliability, the overall kappa value for LIFES was substantial, $\kappa=.78, S E=.01$, $95 \% \mathrm{CI}=[.77, .80], 88.94 \%$ agreement. There was a significant correlation between the lived experiences reported in the self-report condition and the interview condition, $r=.83, p<.001$, suggesting that participants who reported a high number of lived experiences in the self-report condition also reported high values in the interview condition. The majority of domains presented an almost perfect kappa (school: $\kappa=.86, S E=.02,95 \% \mathrm{CI}=[.81, .91], 93.13 \%$ agreement; life conditions: $\kappa=.92, S E=.02,95 \% \mathrm{CI}=$ $[.88, .95], 95.79 \%$ agreement) or a substantial kappa (job: $\kappa=.77, S E=.05,95 \%$ CI $=[.66, .87], 88.31 \%$ agreement; health: $\kappa=.77, S E=.04,95 \% \mathrm{CI}=[.70, .85], 88.81 \%$ agreement; leisure: $\kappa=.63, S E=.04,95 \%$ $\mathrm{CI}=[.55, .71], 84.75 \%$ agreement; and people and relationships: $\kappa=.79, S E=.02,95 \% \mathrm{CI}=[.76, .82]$, $89.15 \%$ agreement). Adverse experiences and accomplishments achieved moderate kappa values, $\kappa=.49$, $S E=.09,95 \% \mathrm{CI}=[.32, .66], 92.11 \%$ agreement and $\kappa=.43, S E=.05,95 \% \mathrm{CI}=[.32, .54], 73.03 \%$ agreement, respectively.

Regarding non-lived experiences, Cohen's kappa was slight, $\kappa=.15, S E=.10,95 \% \mathrm{CI}=[0, .35]$, and the percentage of agreement was 53.5\%. Moreover, $32.1 \%$ of participants reported non-lived experiences in the self-report condition and in the interview condition, $21.4 \%$ did not report non-lived experiences in either condition, and $46.4 \%$ reported non-lived experiences in only one of the conditions. In the selfreport condition, the mean of non-lived experiences was $0.81(S D=1.29$, range $=0-5)$, and that of the interview condition was $0.90(S D=.99$, range $=0-4)$; Pearson's correlation was statistically significant, $r=$ $.28, p=.027$.

\section{Study 4.3: Inter-rater reliability}

Aims. Comparing self-reports with a gold standard is an advisable strategy. However, in many situations, it is not possible for a myriad of reasons, such as difficulties to access gold standards (which usually require multiple authorizations from institutions and individuals) and to gather data; they are limited to specific groups and sensitive to missing data or errors; it could be different to pair gold standards with individual responses; or, in extreme cases, there is no gold standard (Kreuter, Yan, \& Tourangeau, 2008). Considering these problems, and due to the comprehensive and extensive list of life experiences included 
in LIFES, it was not feasible to compare it with gold standards. Consequently, an alternative approach was applied, i.e., the comparison between self-reports and external sources of information, as suggested by Hardt \& Rutter(2004). More specifically, this study aimed to clarify whether answers provided on the self-report were confirmed by collateral informants.

Participants. The participants were 94 twins, organized in 47 pairs, who enrolled in a study about life experiences and health complains. After an initial analysis, ten participants were excluded due to the high discrepancy between the self and collateral reports; therefore, the data from 84 participants were further analyzed. The mean age was 25.82 years $(S D=8.47$, range $=18-50)$, and $71.4 \%$ were female. Most participants were students $(45.2 \%)$ or were employed (40.5\%), $10.7 \%$ were unemployed, and $3.6 \%$ presented another employment status. Regarding marital status, $79.8 \%$ of participants were single, $16.7 \%$ were married, and $3.6 \%$ were divorced. The majority of participants were well educated, considering that $53.6 \%$ had completed high school education and $35.7 \%$ had a graduate degree; the remaining $10.8 \%$ finished only basic education. Most participants $(70.4 \%)$ cohabited with the twin throughout childhood and adolescence, $22.2 \%$ always lived with the twin, and $2.5 \%$ reported living with their twin only throughout adolescence. Regarding the relationship, $90.5 \%$ of participants rated it as good or very good.

Materials and procedures. In addition to the version of LIFES described previously (corresponding to the self-report), the booklet contained an additional set of items from LIFES, focusing on the other twin's experiences (corresponding to the collateral report). To gather data about corroboration, participants were asked only about the occurrence (using a yes or no dichotomous scale) of the experiences to their twins. This subset of 57 items, which was selected independently by three raters, contained experiences that were concrete in the sense that their occurrences were verifiable and independent of subjects' interpretations of the feeling. After institutional approvals, participants were recruited through snowball sampling and advertisements in formal and informal networks. After the presentation of the study and the provision of informed consent, participants completed the booklet individually in a paper-and-pencil format and provided data on demographics and the twins' relationship. To avoid contamination, participants were directly asked to not share or talk about their answers with their twin during the data collection. Regarding data analysis, as described above, the parameters of agreement were computed, comparing in this study the self-report with the collateral report. A special case was made for parents' relationship (items 43-49) because twins shared parents; regarding those items, self-reports from pairs were compared.

Results. Overall, $94.94 \%$ of the self-reported answers were corroborated by the twin, and the agreement was almost perfect, $\kappa=.89, \mathrm{SE}=.01,95 \% \mathrm{CI}=[.87, .90]$. At the domain level, Cohen's kappa ranged from substantial to almost perfect, and the percentage of agreement was above 85 in all domains, i.e.,: $\kappa=.91$, $S E=.02,95 \% \mathrm{CI}=[.88, .95], 95.72 \%$ agreement for school; $\kappa=.87, S E=.03,95 \% \mathrm{CI}=[.81, .93], 93.73 \%$ agreement for job; $\kappa=.79, S E=.04,95 \% \mathrm{CI}=[.71, .87]$, 92.74\% agreement for health; $\kappa=.76, S E=.04$, $95 \% \mathrm{CI}=[.67, .84], 88.26 \%$ agreement for leisure; $\kappa=.93, S E=.02,95 \% \mathrm{CI}=[.90, .97], 97.22 \%$ agreement for life conditions; $\kappa=.74, S E=.08,95 \% \mathrm{CI}=[.60, .89], 97.34 \%$ agreement for adverse experiences; $\kappa=$ $.71, S E=.08,95 \% \mathrm{CI}=[.55, .87], 85.53 \%$ agreement for accomplishments; and $\kappa=.91, S E=.01,95 \% \mathrm{CI}=$ $[.89, .93], 95.67 \%$ agreement for people and relationships. Descriptive and inferential statistics for individual items are presented in Table 4.

\section{DISCUSSION}

This paper provides a comprehensive overview of the development of LIFES, and it describes the validation and reliability of this measure in community samples, providing evidence based on test content, on response processes, on relations to other variables, and on different types of reliability (AERA, APA, \& NCME, 2002). Overall, attending to our several studies, we considered that LIFES presented sound evidence of validation and reliability, which will be summarized and discussed next, independently for lived and non-lived experiences. Once again, it must be stressed that this process was methodologically oriented by life events research, which presents several special characteristics (e.g., Cleary, 1981), resulting in a real challenge (Gray et al., 2004). Indeed, in this case, statistical tests that are a function of item inter-correlations, such as Cronbach's alpha or latent class analysis ${ }^{11}$ (as recently applied byKreuter et al.(2008) and Cloitre, Garvert, Weiss, Carlson, \& Bryant( 2014) are not informative. Attending to all these reasons we applied a formative model, instead of a reflective one.

${ }^{11}$ Applied to categorical variables as an alternative to factorial analysis. 
Regarding lived experiences, a comprehensive and cohesive set of evidence was collected. Experiences assessed in this section emerged from a complex network of sources (e.g., interviews, existing measures) and were well qualified for both experts (evidence based on test content) and participants (evidence based on response processes).

Additionally, empirical evidence provided positive results. For instance, there were no sex differences, but education seemed to affect the reporting of lived experiences; the same patterns were observed by Sarason, Johnson, and Siegel (1978) during the development of the Life Experiences Survey. The findings also confirmed a commonly accepted notion of age, suggesting that older individuals reported more lived experiences. Moreover, there were no differences in the total of lived experiences based on psychological distress, but distressed individuals presented significantly more negative experiences and fewer positive experiences than those who were not distressed. In the same direction, concerning the association between LIFES and BSI, the results were clear and conformed to our expectations: Participants with a larger number of negative lived experiences reported higher levels of psychological symptoms, whereas the opposite was observed for positive lived experiences. The literature about negative life events and their psychological effects (e.g., depression and anxiety) is extensive and supports our findings (e.g., Edwards, Holden, Anda, \& Felitti, 2003). The small number of studies about positive experiences and their inconclusive results make the appropriate comparisons difficult. For instance, Overbeek et al. (2010) observed that individuals with mood disorders reported more positive experiences; however, Swearingen and Cohen (1985) found negative (but nonsignificant) correlations between the number of positive events and depression and state anxiety. .

Despite the difficulty to compare LIFES with similar measures, evidence based on convergent validity is encouraging and clear: Overall, the levels of agreement and correlations were good when LIFES was compared with ACE and LES. A deeper analysis of the data revealed that disagreements were associated with a mismatching of the developmental stage of occurrence or of the third parties involved. The convergent validity of LIFES and LES was higher than of LIFES and ACE, suggesting that life experiences that occurred in adulthood were reported similarly in the two measures. These results can be explained by the greater similarity between LIFES and LES (e.g., wording), the type of experiences assessed in childhood/adolescence and adulthood (more concrete and time limited in adulthood), and the fact that LIFES is more comprehensive than ACE regarding the people involved. For instance, whereas LIFES considered interparental violence from father to mother and vice-versa, ACE asked only father-tomother violence. Lastly, a slightly higher overall value of agreement was achieved by temporal reliability $(\kappa=.82,90.59 \%$ agreement $)$ than by cross-method reliability $(\kappa=.78,88.94 \%$ agreement $)$, with an increasing number of reported experiences at T2 in both conditions. Generally, percentages of agreement in temporal and in inter-method reliability were similar across items, and the data did not show a clear advantage of a singular design (i.e., some items presented a high agreement on temporal design, whereas others presented a high agreement on inter-method design). Due to the low number of participants analyzed, these results should be further extended, although it is reasonable to suspect that some items benefit from the advantages of self-reports (e.g., privacy), whereas others benefit from the interviews' advantages (e.g., clarification of questions). Nevertheless, our results are not surprising or exclusive of LIFES; indeed, Goodman, Corcoran, Turner, Yuan, and Green (1998) reported a similar trend when they studied the psychometric properties of the Stressful Life Events Screening Questionnaire, and Krinsley, Gallagher, Weathers, Kutter, and Kaloupek (2003) achieved the same conclusions regarding the Evaluation of Lifetime Stressors. Collateral reporting is also a strategy to assess reliability, particularly when it is difficult (or impossible, as happens in many LIFES items) to check against gold standards. Despite some concerns regarding the information provided in some situations (Fisher, Bunn, Jacobs, Moran, \& Bifulco, 2011), family members seem to be preferential collaterals in this field of research (Hardt \& Rutter, 2004). Our inter-rater study analyzed twins, and almost 95\% of the responses from selfreports were confirmed by the collateral; in a similar study comparing sisters and childhood/adolescence experiences, Bifulco, Brown, Lillie, and Jarvis (1997) also found substantial agreement, concluding that the results supported the confidence about retrospective data collection.

To the best of our knowledge, non-lived experiences are not included in any similar measure but are a major characteristic of LIFES, and they deserve comment. First, less evidence was gathered regarding this section than lived experiences; indeed, comparing against a similar measure was not possible, and asking for collateral about others' non-lived experiences seems odd. Second, the empirical results seem not to be as clear as those from the first section. Regarding convergent and discriminant evidence, only education significantly affected the number of non-lived experiences, but differences disappeared at the group level. An analysis of the descriptive data suggested that older and less educated participants reported fewer non-lived experiences. Similarly, the results regarding reliability were ambiguous: Whereas temporal reliability achieved a substantial kappa, cross-method reliability 
presented only a slight kappa. Notwithstanding, the number of non-lived experiences increased in both studies at $\mathrm{T} 2$.

Overall, these results sound reasonable for a myriad of reasons and should not be discouraging. First, as mentioned previously, non-lived experiences are described in blank spaces for each developmental stage, whereas lived experiences are represented by an established list of items. Research focused on methodological issues has found that open- and closed-ended questions present both advantages and disadvantages, and they can produce different results, with open-ended being more flexible (Fowler, 1995; Tourangeau, Rips, \& Rasinski, 2000). Second, the results seemed cohesive when we thought about the construct of life experiences (not lived but desired) and the correlations presented regarding the first section (such as age, education, and psychological disturbance). In this line of thought, Segal, Wood, DeMeis, and Smith (2003) found a positive correlation between depression and future negative events when they evaluated a sample of young adults using the Anticipated Life History. Almeida, Wethington, and Kessler (2002) concluded that daily stressors appraised as interfering with plans for the future predicted negative mood. Additionally, it should be noted that most people are not used to being asked about non-lived experiences; therefore, it is reasonable to think that an increased familiarity with the task would produce clearer results.

A special remark should be made regarding Cohen's kappa, the statistical analysis computed to assess reliability (temporal, inter-method, and inter-rater) and the convergent validity. Although Cohen's kappa is the most common statistical test to assess the psychometric properties of life experience measures, it tends to reveal a well-documented pitfall (Feinstein \& Cicchetti, 1990): Some items presented very low kappa values, although the percentages of agreement were high. This phenomenon, which was evidenced in some individual items and domains of LIFES and have also been reported by other researchers (e.g., Gray et al., 2004), can be observed in infrequent phenomena (e.g., Viera \& Garrett, 2005) or due to a marginal distribution (Lantz \& Nebenzahl, 1996; Feinstein \& Cicchetti, 1990; Cicchetti \& Feinstein, 1990). As far as we know, there is no option to replace Cohen's kappa when variables under study are nominal; therefore, as suggested by Fleiss, Levin, and Paik (2003), and according to the guidelines proposed by Kottner et al. (2011), we presented several parameters (i.e., percentage of agreement, Cohen's kappa, standard error, and confidence intervals) to allow for a deeper knowledge about our data.

Recognizing that no measure or evaluating process is perfect, some limitations should be acknowledged. First, according to Zimmerman (1983), "any life event scale, regardless of its length, contains only a subset of the universe of possibly life situations, and no list is likely to be comprehensive for all individuals" (p. 347); the same applies to LIFES. Although it covers a comprehensive set of life experiences, LIFES fails to include others that occur specifically in some populations (e.g., inmates); therefore, when applied to other target populations, this type of measure will benefit from adaptations, as recommended by Cleary (1981). Second, the dimension and the composition of the samples are also a major concern, particularly regarding reliability studies and non-lived experiences. For instance, Schönbrodt and Perugini (2013) recommended a minimum sample of 250 for typical studies, admitting fewer participants when the expected correlation was greater (as happens in the case of the reliability studies and when the construct under study is expected to be stable ${ }^{12}$ ). Although there is some guidance for sample-size calculations for kappa (e.g., Cantor, 1996), as Hadzi-Pavlovic (2010) noted, "power estimation for kappa is not as firmly developed as it is for some other commonly used statistics and the estimates are more approximate" (p.199), and it usually involves a priori estimates about the expected proportions of answers and marginal frequencies, which are difficult to establish if we are evaluating a new measure. Adults from the community were our target population, and few exclusion criteria were established; however, our samples reflected a common pattern in scientific research composed primarily of female, younger, educated and employed individuals (Patel, Doku, \& Tennakoon, 2003). Although the inclusion of non-lived experiences fulfills a gap, the results obtained are clearly exploratory; indeed, few participants reported non-lived experiences, which compromised sound conclusions about this section. Lastly, LIFES may also be influenced by other well-known variables that affect self-reports in general and life experience measures in particular, such as memory issues (minimized by the inclusion of the not remember option), mood or willingness to report (e.g., Hardt \& Rutter, 2004).

We are aware that collecting sound psychometric evidence is a process of accumulating evidence (AERA, APA, \& NCME, 2002); consequently, future studies are highly recommended. Due to our concerns about sampling, future studies should be designed to increase the number and heterogeneity of participants; moreover, clinical samples and specific groups (e.g., elderly, ethnic minorities) should be

\footnotetext{
12 Although life experiences reported can change, due to new experiences or memory issues, they are not expected to be as prone to change
} as other constructs involving attitudes or opinions. 
studied to replicate and extend the findings presented here. Additionally, we recommend that research continue to examine the cross-cultural and linguistic relevance of LIFES in other languages and cultures. According to our experience throughout this process, as noted by Patel et al. (2003), difficulties in recruitment (particularly for longitudinal studies) and flexibility regarding data collection methods would be the greatest challenges for these studies. Regarding non-lived experiences, considering that both experts and participants noted its relevance and meaningfulness, this section deserves further attention and should be deeply explored in future studies. Furthermore, it would be useful to collect additional evidence through a different approach of temporal reliability, using interviews at both assessments, or to include other informants on inter-rater reliability. Consequently, despite being promising, the analyses presented can be considered preliminary, and a continuing effort should be made to gather more data about LIFES.

Lastly, a comment should be made about the implications and applications of LIFES. Being an old concern (Paykel, 2001), life experiences are still embedded across almost all fields of psychology. Usually, life experience measures are widely used for years before their psychometric evidence is gathered, likely due to the specificities and difficulties involved. In an effort to reverse this trend, we presented comprehensive evidence about a new measure, which fulfills a gap in this field of research. Due to LIFES's strengths and characteristics, it is a valuable and useful tool not only for research but also for practical purposes. It allows simply and effectively gathering a broad picture of what occurred during an individual's life.

\section{REFERENCES}

Almeida, D. M., Wethington, E., \& Kessler, R. C. (2002). The Daily Inventory of Stressful Events: An interview-based approach for measuring daily stressors. Assessment, 9(1), 41-55. https://doi.org/10.1177/1073191102091006

American Educational Research Association, American Psychological Association, National Council on Measurement in Education (2002). Standards of educational and psychological testing. American Educational Research Association.

American Psychological Association (2016). Glossary of psychological terms. http://www.apa.org/research/action/glossary.aspx?tab=17

Bausmeister, R. F., Bratslavsky, E., Finkenauer, C., \& Vohs, K. D. (2001). Bad is stronger than good. Review of General Psychology, 5(4), 323-370. https://doi.org/10.1037/1089-2680.5.4.323

Bifulco, A., Brown, G. W., Lillie, A., \& Jarvis, J. (1997). Memories of childhood neglect and abuse: Corroboration in a series of sisters. Journal of Child Psychology and Psychiatry , 38(3), 365-374. https://doi.org/10.1111/j.1469-7610.1997.tb01520.x

Bollen, K. A; \& Bauldry, S. (2011). Three Cs in measurement models: Causal indicators, composite indicators, and covariates. Psychological Methods, 16(3), 265-284. http://dx.doi.org/10.1037/a0024448

Burt, C. D. B., Kemp, S. \& Conway, M. A. (2003). Themes, events, and episodes in autobiographical memory. Memory \& Cognition, 31(2), 317-325. https://doi.org/10.3758/BF03194390

Canavarro, M. C. (2007). Inventário de Sintomas Psicopatológicos. In M. Simões, C. Machado, M. Gonçalves, \& L. Almeida (Eds.), Avaliação psicológica: Instrumentos validados para a população portuguesa (Vol. III, pp. 305-331). Quarteto Editora.

Cantor, A. B. (1996). Sample-size calculations for Cohen 's kappa. Psychological Methods, 1(2), 150-153. https://doi.org/10.1037/1082-989X.1.2.150

Casey, R. L., Masuda, M., \& Holmes, T. H. (1967). Quantitative study of recall of life events. Journal of Psychosomatic Research, 11(2), 239-247. https://doi.org/10.1016/0022-3999(67)90013-X

Cicchetti, D. V., \& Feinstein, A. R. (1990). High agreement but low kappa: II. Resolving the paradoxes. Journal of Clinical Epidemiology, 43(6), 551-558. https://doi.org/10.1016/0895-4356(90)90159-M

Cleary, P. J. (1980). A checklist for life event research. Journal of Psychosomatic Research, 24, 199-207. https://doi.org/10.1016/0022-3999(80)90042-2

Cleary, P. J. (1981). Problems of internal consistency and scaling in life events schedules. Journal of Psychosomatic Research, 25(4), 309-320. https://doi.org/10.1016/0022-3999(81)90008-8

Cloitre, M., Garvert, D. W., Weiss, B., Carlson, E. B., \& Bryant, R. A. (2014). Distinguishing PTSD, complex PTSD, and borderline personality disorder: A latent class analysis. European Journal of Psychotraumatology, 5, 1-10. https://doi.org/10.3402/ejpt.v5.25097

Cohen, J. (1960). A coefficient for nominal scales. Educational and Psychological Measurement, 20, 37-46. https://doi.org/10.1177/001316446002000104 
Coltman, T. , Devinney, T. M., Midgley, D. F., \& Venaik, S. (2008). Formative versus reflective measurement models: Two applications of erroneous measurement. Journal of Business Research, 61(12), 12501262. https://doi.org/10.1016/j.jbusres.2008.01.013

Conway, M. A. (2005). Memory and the self. Journal of Memory and Language, 53, 594-628. https://doi.org/10.1016/j.jml.2005.08.005

Conway, M. A. , \& Pleydell-Pearce, C. W. (2000). The construction of autobiographical memories in the self-memory system. Psychological Review, 107, 261-288. https://doi.org/10.1037/0033295X.107.2.261

Cook, D. A., \& Beckman, T. J. (2006). Current concepts in validity and reliability for psychometric instruments: Theory and application. The American Journal of Medicine, 119, 166.e7-166.e16. https://doi.org/10.1016/j.amjmed.2005.10.036

Derogatis, L. R. (1993). BSI Brief Symptom Inventory: Administration, scoring and procedure manual (4th Ed.). National Computers Systems.

Dohrenwend, B. P. (2006). Inventoring stress life events as risks factors for psychopathology: Toward resolution of the problema of intracategory variability. Psychological Bulletin, 132(2), 477-495. https://doi.org/10.1037/0033-2909.132.3.477

Edwards, J. R., \& Bagozzi, R. P. (2000). On the nature and direction of relationships between constructs and measures. Psychological Methods, 5(2), 155-174. https://doi.org/10.1037/1082-989X.5.2.155

Edwards, V. J., Holden, G. W., Anda, R. F., \& Felitti, V. J. (2003). Relationship between multiple forms of childhood maltreatment in community respondents: Results from the Adverse Childhood Experience Study. American Journal of Psychiatry, 160(8), 1453-1460. https://doi.org/10.1176/appi.ajp.160.8.1453

Feinstein, A. R., \& Cicchetti, D. V. (1990). High agreement but low kappa: I.The problems of two paradoxes. Journal of Clinical Epidemiology, 43(6), 543-549. https://doi.org/10.1016/0895-4356(90)90158-L

Felitti, V. J., Anda, R. F., Nordenberg, D., Williamson, D. F., Spitz, A. M., Edwards, V., Koss, M. P., \& Marks, J. S. (1998). Relationship of childhood abuse and household dysfunction to many of the leading causes of death in adults. American Journal of Preventive Medicine, 14, 245-258. https://doi.org/10.1016/S0749-3797(98)00017-8

Fisher, H. L., Bunn, A., Jacobs, C., Moran, P., \& Bifulco, A. (2011). Concordance between mother and offspring retrospective reports of childhood adversity. Child Abuse and Neglect, 35(2), 117-122. https://doi.org/10.1016/j.chiabu.2010.10.003

Fleiss, J. L., Levin, B., \& Paik, M. C. (2003). The measurement of interrater agreement. Statistical methods for rates and proportions (3rd ed., pp. 598-626). John Wiley \& Sons.

Fowler, F. J. (1995). Improving survey questions: Design and evaluation. In L. Bickman, \& D. J. Rog (Series Eds.), Applied Social Research Method Series : Vol. 38. SAGE Publications.

Gersten, J. C., Langner, T. S., Eisenberg, J. G., \& Orzek, L. (1974). Child behavior and life events: Undesirable change or change per se? In B. S. Dohrenwend, \& B. P. Dohrenwend (Eds.), Stressful life events: Their nature and effect (pp.159-170). John Willey and Sons.

Goodman, L. A., Corcoran, C., Turner, K., Yuan, N., \& Green, B. L. (1998). Assessing traumatic event exposure: General issues and preliminary findings for the Stressful Life Events Screening Questionnaire. Journal of Traumatic Stress, 11(3), 521-542. https://doi.org/10.1023/A:1024456713321

Gray, M. J., Litz, B. T., Hsu, J. L., \& Lombardo, T. W. (2004). Psychometric properties of the Life Events Checklist. Assessment, 11(4), 330-341. https://doi.org/10.1177/1073191104269954

Hadzi-Pavlovic, D. (2010). Sample size for kappa. Acta Neuropsychiatrica, 22(4), $199-201$. https://doi.org/10.1111/j.1601-5215.2010.00479.x

Hardt, J., \& Rutter, M. (2004). Validity of adult retrospective reports of adverse childhood experiences: Review of the evidence. Journal of Child Psychology and Psychiatry, 45(2), 260-273. https://doi.org/10.1111/j.1469-7610.2004.00218.x

Hooper, L. M., Stockton, P., Krupnick, J. L., \& Green, B. L. (2011). Development, use and psychometric properties of the Trauma History Questionnaire. Journal of Loss and Trauma, 16, 258-283. https://doi.org/10.1080/15325024.2011.572035

Kottner, J., Audige, L., Brorson, S., Donner, A., Gajewski, B.J., Hróbjartsson, ... Streiner, D. L. (2011). Guidelines for reporting reliability and agreement studies (GRAAS) were proposed. Journal of Clinical Epidemiology, 48(6), 661-671. https://doi.org/10.1016/j.ijnurstu.2011.01.016

Kreuter, F., Yan, T., \& Tourangeau, R. (2008). Good item or bad - can latent class analysis tell?: The utility of latent class analysis for the evaluation of survey questions. Journal of the Royal Statistical Society: Series A (Statistics in Society), 171(3), 723-738. https://doi.org/10.1111/j.1467985X.2007.00530.x 
Krinsley, K. E., Gallagher, J. G., Weathers, F. W., Kutter, C. J., \& Kaloupek, D. G. (2003). Consistency of retrospective reporting about exposure to traumatic events. Journal of Traumatic Stress, 16(4), 399-409. https://doi.org/10.1023/A:1024474204233

Landis, J. R., \& Koch, G. G. (1977). The measurement of observer agreement for categorical data. Biometrics, 33(1), 159-174.

Lantz, C. A., \& Nebenzahl, E. (1996). Behavior and interpretation of the k statistic: Resolution ot the two paradoxes. Journal of Clinical Psychology, 49(9), 431-434. https://doi.org/10.1016/08954356(95)00571-4

Netland, M. (2005). Event-list construction and treatment of exposure data in research on political violence. Journal of Traumatic Stress, 18(5), 507-517. https://doi.org/10.1002/jts.20059

Overbeek, G., Vermulst, A., Graaf, R., Have, M., Engels, R., \& Scholte, R. (2010). Positive life events and mood disorders: Longitudinal evidence for an erratic life course hypothesis. Journal of Psychiatric Research, 44, 1095-1100. https://doi.org/10.1016/j.jpsychires.2010.03.019

Patel, M. X., Doku, V., \& Tennakoon, L. (2003). Challenges in recruitment of research participants. Advances in Psychiatric Treatment, 9(3), 229-238. https://doi.org/10.1192/apt.9.3.229

Paykel, E. S. (1983). Methodological aspects of life events research. Journal of Psychosomatic Research, 27(5), 341-352. https://doi.org/10.1016/0022-3999(83)90065-X

Paykel, E. S. (2001). The evolution of life events research in psychiatry. Journal of Affective Disorders, 62, 141-149. https://doi.org/10.1016/S0165-0327(00)00174-9

Pedro, C. R. R., \& Pinto, R. (2013). The relationship between childhood adversity, psychopathology symptoms, and life experiences (Unpublished master's thesis). Universidade Lusófona: Porto.

Sarason, I. G., Johnson, J. H., \& Siegel, J. M. (1978). Assessing the impact of life changes: Development of the life experiences survey. Journal of Consulting and Clinical Psychology, 46(5), 932-946. https://doi.org/10.1037/0022-006X.46.5.932

Schönbrodt, F. D., \& Perugini, M. (2013). At what sample size do correlations stabilize? Journal of Research in Personality, 47(5), 609-612. https://doi.org/10.1016/j.jrp.2013.05.009

Segal, H. G., Wood, G. a., DeMeis, D. K., \& Smith, H. L. (2003). Future events, early experience, and mental health: Clinical assessment using the Anticipated Life History Measure. Assessment, 10(1), 29-40. https://doi.org/10.1177/1073191102250186

Silva, S., \& Maia, A. (2008). Versão portuguesa do Family ACE Questionnaire (Questionário de História de Adversidade na Infância). In A. P. Noronha, C. Machado, L. Almeida, M. Gonçalves, S. Martins, \& V. Ramalho (Eds.), Actas da XIII Conferência Avaliação Psicológica: Formas e Contextos. Psiquilibrios Edições.

Swearingen, E. M., \& Cohen, L. H. (1985). Measurement of adolescents' life events: The junior high life experiences survey. American Journal of Community Psychology, 13(1), 69-85. https://doi.org/10.1007/BF00923260

Tourangeau, R., Rips, L. J., \& Rasinski, K. (2000). The psychology of survey response. Cambridge University Press.

Viera, A. J., \& Garrett, J. M. (2005). Understanding interobserver agreement: The kappa statistic. Family Medicine, 37(5), 360-363.

Zimmerman, M. (1983). Methodological issues in the assessment of life events: A review of issues and research. Clinical Psychology Review, 3, 339-370. https://doi.org/10.1016/0272-7358(83)90019-3

Historial do artigo

Recebido $\quad 02 / 2019$

Aceite $\quad 06 / 2020$

Publicado 08/2020 